\title{
Food for all?: Critically evaluating the role of the Incredible Edible movement in the UK
}

\author{
Michael Hardman, Mags Adams, Melissa Barker \\ and Luke Beesley
}

\section{Introduction}

The practice of Urban Agriculture (UA) - the growing of food and/or rearing of livestock within the city context - is on the rise globally (Hardman and Larkham, 2014). Arguments for UA vary, ranging from its potential to contract the food supply chain by relocating production closer to urban consumers, to the potential for improved social engagement, through bringing communities together on allotments, communal gardens and other growing spaces (Gorgolewski et al., 2011; Wiskereke and Viljoen, 2012). Proponents of UA often cite Detroit (USA) and Havana (Cuba) as exemplars in which such practices have resulted in various positive impacts: regenerating space, feeding people in need and creating sustainable economies (Giorda, 2012). An emerging argument in Europe surrounds the potential for UA to create a more 'just' food system (Alkon and Agyeman, 2011). Whilst the link between food justice and UA has a nascent research base in North America, there is little exploration elsewhere, particularly in the UK (Tornaghi, 2014). There is also emerging research which focuses on the environmental benefits derived through UA, particularly its contribution to local ecosystems and usage of urban by-products as growing substrates (Chipungu et al., 2013). Conversely there are warnings sounded in recent literature about the risks canciated with UA, particularly in relation to the contaminated soils and waters

P. Ch urban growing projects could be exposed to (Chipungu et al., 2013).

At its most basic level UA involves bringing food production into the cityscape (Caputo, 2012): from community gardens and allotments, to radical vertical 
cultivating systems and rooftop farms, all constitute examples of UA in practice (Gorgolewski et al., 2011).Whilst allotment gardening has been embedded within UK culture for some time, new forms of UA - such as community gardening are only just gaining momentum. The core argument for UA is often based on the need for greater food security; with global population increasing and the rapid growth of cities, the way we cultivate crops is being reconsidered (Wiskerke and Viljoen, 2012). Fundamentally UA challenges the idea that the urban and rural are separate spaces and that the city is a place outside nature with the rural forming the productive heartland (Scott et al., 2013).

This chapter provides an interdisciplinary evaluation of the role of local food initiatives, such as Incredible Edible Todmorden (IET), in creating more just food systems. The Incredible Edible movement emanated from a small town in England; with informal roots it started in 2008 through guerrilla gardening practices before legalising and growing into a formal collective (IET, 2017). The movement now crosses the globe and is a popular model replicated in a variety of urban areas across the UK. Across Europe, and particularly in the UK, similar initiatives are becoming more popular, receiving large amounts of praise and public funds to advance their work. Despite this, to date there is little critical analysis of these popular UA schemes. Often such projects are assumed to be inherently 'good' since actions are devolved to the local scale (see Born and Purcell, 2009) and yet recent literature shows that there is more to these practices which requires further investigation, including concerns about participation and exclusion, about risk and safety and about democratic decision-making (see for instance Allen, 2014; Hardman and Larkham, 2014). Furthermore, whilst there is a distinct lack of objectivity with regards to their impact, there is also a general lack of data on crop yields and consumption as well as the safety of such practices in terms of crops becoming contaminated (Chipungu et al., 2013).

Drawing on research on the Incredible Edible movement, this chapter questions the extent to which local food initiatives can be said to be inclusive, with regards to involving the wider community, and what this means in terms of any such small-scale UA being viewed as contributing to food justice. Of particular focus is its ability to empower communities to grow, sell or eat healthy produce, the key principles underpinning the concept of food justice. A mixed methods approach is employed to critically evaluate the movement and its impact on communities, drawing on both qualitative and quantitative data to provide an in-depth exploration of its value to inner-city communities. The chapter critically evaluates a number of taken-for-granted assumptions about the role and place of such local food initiatives and suggests ways in which local food initiatives might be better structured to contribute to food sovereignty. In addition to this, the chapter presents an insight into the risks associated with the 'grow it anywhere' philosophy in terms of the lack of access to safe and fertile soils in urban centres and the subsequent adoption of UA practices on potentially contaminated land. 


\section{The rise of urban agriculture: informal to formal}

Whilst allotment gardening has been popular globally, particularly in the UK, new forms of UA are on the rise: community gardens, urban farms, high-tech growing and other activities are increasing in cityscapes (Wiskerke and Viljoen, 2012). Indeed, the latter forms mostly originated from American practice and have had a strong influence on other parts of the world. The often-communal nature of the UA activity is a draw to communities who often see the spaces as a mechanism for cohesion and beautification (Tornaghi, 2014). Many of these spaces started through informal activity, in which guerrilla gardeners adopted land without permission, often due to oversubscription of allotment plots (Hardman and Larkham, 2014).

There is very little academic exploration of those who practise UA informally, despite the fact that many of the most visible, community engaged and productive growing projects around the globe started through such action (Crane et al., 2012; Reynolds, 2008). The term 'guerrilla gardener' is often attached to those who pursue such an agenda; an umbrella term for a form of growing activity which does not have the necessary permission such as planning consent or landowner agreement (Johnson, 2011; McKay, 2011; Tornaghi, 2014). Although guerrilla gardening is often viewed as a small-scale activity and is often undertaken for thrills or for urban beautification rather than food production, the activity may also involve large-scale cultivation, with unpermitted community gardens and urban farms falling under the umbrella term (Hardman and Larkham, 2014).

\section{The informal movement}

Guerrilla gardening is practised worldwide. From the 'trendy' and relatively 'soft' intransigent political movements in North America and Europe, to those pursuing it for survival in Africa and other global South nations, the activity is very broad (Adams et al., 2014; Reynolds, 2008). In the case of Africa, most of the UA practised across the continent could be viewed as guerrilla gardening, as city authorities and national governments often discourage the practice of UA (Chipungu et al., 2013). In a similar manner, residents of Havana, Cuba - one of the most frequently cited exemplars of UA - faced barriers from authorities and originally practised guerrilla gardening (Hardman and Larkham, 2014). Once the positive aspects of UA were realised, municipal authorities encouraged the activity and provided support, along with guidance, for those interested in growing across Havana (Viljoen, 2005).

Despite these examples, it is usually the subversive, illegal aspects of guerrilla gardening, with participants colonising land under the cover of darkness, which more often attracts media interest (Lewis, 2012). The modern movement began with the Green Guerillas (sic) who beautified neglected spaces across 
New York City in the 1970s. The creation of the website guerrillagardening. org, by Richard Reynolds in 2004, brought the guerrilla gardening movement up to date, widening its profile and enabling participants to connect through the internet and social media before carrying out any action (Reynolds, 2008). The movement has grown rapidly, with social media enabling guerrillas to share and plan action on a scale never seen before; but even so the guerrilla focus on edible productivity is small, in common with many guerrilla projects in general (see Hardman and Larkham, 2014).

Although there may be a media-led stereotypical image of a guerrilla gardener being a young hipster who plants flowers to beautify an area, research about those involved reveals that a wide variety of individuals including businessmen, professionals and retired people take part in the action (Adams and Hardman, 2014). The action is increasingly involving the planting of edibles, with schemes such as IET providing evidence that guerrilla gardening can facilitate UA on a large scale. In this case, residents of Todmorden - a small town in West Yorkshire - adopted sites across the locality to plant a variety of produce (IET, 2017). The scheme was so successful that a large international network evolved, with other towns and cities replicating the Incredible Edible concept.

This, and evidence from several academic studies, suggests that guerrilla gardening has acted as a mechanism for much larger green movements (see for instance Crane, 2011; McKay, 2011; Zanetti, 2007). It has enabled people to have greater access to food and started many more formal movements; an example of such impact can be seen in the many case studies exhibited in On Guerrilla Gardening, a textbook on how to go about guerrilla gardening by Richard Reynolds (2008). Reynolds shows how guerrilla gardening has enabled people to have greater access to greenspace and how it has significantly changed a wide range of urban sites; from inside prisons to underground areas and on the street corner, every space can potentially be colonised and made useful.

Whilst guerrilla gardening practices generate many positive impacts, from the ability to engage people in innovative ways to beautifying spaces or growing food for those who require it (Reynolds, 2008), there are also problematic aspects to the activity. For instance, Allen (2014) argues that guerrilla gardening is a reactionary activity and that the activity is not a solution to the oppressive force of powerful elites who control elements of urban space stewardship. He also draws attention to how the guerrillas perform their activities without obtaining the permission of the local authority or landowner, and for failing to consult with local communities and 'guardians' active in the area (Allen, 2014). This view is substantiated through research conducted by Hardman and Larkham (2014), who demonstrate how guerrilla gardening can have negative impacts ranging from the lack of maintenance of colonised spaces, to the guerrilla activity designedly excluding those who surround the areas. 


\section{Incredible Edible Todmorden (IET)}

IET started through guerrilla gardening and is perhaps the most successful project of its kind originating from the informal route. Frustrated with a lack of authority support, community members started planting across the town, using leftover space to create havens of production (IET, 2017). After raising awareness of their cause and demonstrating the potential of UA, the group legitimised and found the Incredible Edible movement. Following success in Todmorden the concept spread elsewhere, first in the UK and then globally. There are now over 100 movements who fall under the umbrella of the recently created Incredible Edible Network. The Incredible Edible model differs somewhat to other UA movement in that the focus is to grow everywhere; using train platforms, emergency service stations and even graveyards. This 'out of the box' thinking has made the movement popular and the creation of an easy to use toolkit by the Todmorden element has enabled others to follow their model, obtaining funding and using similar organisational structures to coordinate activities.

This chapter focuses explicitly on the Todmorden case of this global movement, the reason being that this was the catalyst and focal point for the concept's growth. We adopted a qualitative approach to exploring the town and movement, using observational and semi-structured interviews with an array of actors. These actors involved members of the IET committee alongside community members, not all of which were involved in the UA activities. Observations focused on the use of the sites and the project's development, providing an extra dimension to the interview material.

The focus of the interviews was $Q$ nmunity members, although some IET members were interviewed too, notably Mary Clear (Chairperson) and volunteers. Community interviewees were sought from across Todmorden, particularly from those not previously involved in the project. A wide selection of the community was interviewed, all ranging in terms of gender, age and social status. Confidentiality was paramount in this study, due to the small size of the site in question and closeness of the community.

\section{Results: engaging the community}

Incredible Edible Todmorden is putting the unremarkable Todmorden on the map.

(Paull, 2011: 29)

Starting in 2008 with small community plots and herb gardens the focus was to get the town talking about food. Mary Clear, the Chair of Incredible Edible Todmorden, gave a brief description of their ethos in an interview: "we are volunteers from Todmorden who spend a little or a lot of time in this Incredible group, we grow food for sharing around the town in all sorts of places and are very passionate people working together to create a better world for ourselves and 
the planet, food is a unifying theme; if you eat you're in!' Linking to the guerrilla gardening theme earlier, a volunteer adds to Mary's quote by showing how the movement started through informal activity, 'we had permission for the most part but sometimes you just have to dive straight in, no one was using the derelict land outside the Abraham Ormerod Centre so we thought this would be a perfect place to start growing some vegetables'.

One could argue that IET is perhaps one of the most successful guerrilla projects globally due to its sustainability and impact on other towns/cities. This is almost unheard of in terms of guerrilla gardening, with perhaps only the New York 'Green Guerillas' (with one ' $r$ ') as one other example. This is mainly due to the often sporadic and unordered nature of guerrilla gardening, in which the 'thrill' element is often the drive, perhaps alongside a passion for the community and to create more aesthetically pleasing spaces (McKay, 2011). Todmorden turns this on its head and shows the potential of guerrilla gardening; it is not merely small-scale in nature but can spring into large, successful and sustainable initiatives.

In Todmorden alone several interviewees quote that one third of residents are involved in the project, this equates to some 5,200 citizens according to the latest census of the town. The sheer volume of growing locations and the innovative branding certainly appears to have galvanised interest among residents. Nevertheless, as Figure 9.1 demonstrates, IET is much more than merely growing; the scheme also promotes the wider concept of urban sustainability, through embedding beehives and other features throughout the town.

Much like the guerrilla gardening movement, to date there has been no critical exploration of the IET scheme. Rather, mainstream press and academic articles provide a positive overview of the project and its impact, with little critique. Although we do not wish to purposely critique IET in this chapter, we do follow the principles of Born and Purcell's (2009) 'local trap' which urges academics to critically question the common assumption that local is good. In this sense we aimed to engage with local residents and to understand the real role of local food in the Todmorden context.

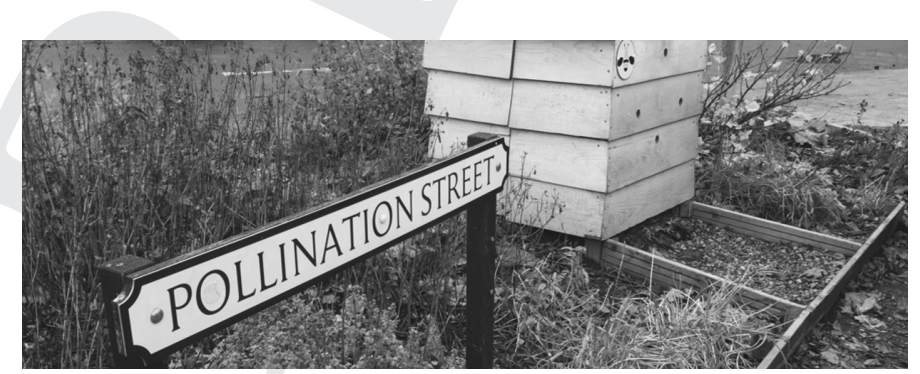

Figure 9.1 A beehive in the middle of a busy Todmorden town centre car park 
Over twenty semi-structured interviews took place, in which local residents of Todmorden were asked a series of open-ended questions about Incredible Edible and their opinions about the programme's work; Grounded Theory's point of saturation was used to influence sample size (Glaser and Strauss, 1967). These interviews largely took place in 2015/16 and were conducted by researcher Barker, a resident of the town herself. They ranged from more informal conversations of 20-30 minutes to an hour apiece. Thematic analysis was used to review the data collected, with participants anonymised to protect identities.

One of the first questions asked during the semi-structured interviews was 'what does the expression Incredible Edible mean to you?' This was in order to gain a basic understanding of local perceptions towards the overarching concept. One Todmorden resident answered: 'IE is an organisation run by local people growing food around the town which is very community based and they try to involve as many people as possible.' The resident has a clear view of work IET undertakes and is similar to the definitions within the literature. In contrast, another resident argued that IET is 'not much really, nothing even. It is not all that incredible in my eyes'. This starts to show that not all views on IET are positive, indeed many residents held critical views on the group's practices. We now proceed to delve deeper into the scheme and review its wider impacts, in terms of creating a more just food system and the hindrances of the model.

\section{Creating a just food system}

The core focus of this chapter is around IET as a potential tool for enabling a more just food system: was it able to enable residents to grow their own and create a thriving local food system? Or were there hidden barriers and issues lurking beneath the overwhelmingly positive media coverage of the scheme? The vast majority of the residents that were interviewed had positive impressions of IET, indeed all interviewees mentioned positive attributes of the scheme. In response to a question based upon first impressions of IE and how these impressions have changed over time, the residents felt it was a good concept based on a clever idea. One resident replied to the question saying 'definitely, its food everybody is entitled to pick what they want, herbs especially, I have known of people going and picking a few leaves and taking them with them'. This appears to be another common theme, as other residents often explained how the growing of food is a positive activity and acts as a good source for extra food and vegetables. It is a scheme that appears to benefit the town, and according to one resident it is "better than going to the supermarkets if locally produced food can be gathered for free instead'. Indeed, this connects well with the idea of food justice, in which a more resilient local food system is at the heart of the concept; in this case it appears that IET is making this a realisation. 
A second positive theme derived from the interviews surrounded social cohesion, with an elderly resident explaining that 'there is this community togetherness surrounding it which is good and it makes the town look better I think, also environmentally speaking it is definitely a good thing growing your own food and not relying on supermarkets'. This connected well with an argument by Breitbach (2007) that the social element is an important factor in a more just food system, enabling communities to share practice, form relationships and work together on wider goals. Adding to this another community member argues that the aesthetic value is also a huge positive alongside the community benefits: 'it also makes the town look better, brightens up the place, it is nice to see vegetables springing up in different areas of Todmorden'.

The economic impact was also mentioned by numerous interviewees, particularly the tourism value of IET. One such resident argued: 'I think it benefits the town not only by growing food but in recent years by bringing tourism to the area, it is attracting so much attention from people all round the world, and they now come for tours around Todmorden.' Indeed, observations during this study showed tourists from as far as Japan and the United States making stops in Todmorden to witness IET first-hand. The popularity has even drawn in royalty, as a proud resident described: "it is probably the most well-known thing about the town at the moment, Prince Charles came to visit it a few years ago which was good, it brought a lot of positivity and the town really came together'.

The tourism factor generates revenue through formal talks organised by IET members. The tours charge a generous price per head and involve a two-hour exploration of the various growing schemes, enabling visitors to experience IET's impressive (and ever-expanding) sites; the space, depicted in Figure 9.2, demonstrates the open nature of the food-growing sites across the town. The tourists are often obliged to stay in the Yorkshire town and thus contribute to the local economy in a more direct way. It still remains that the key focus of this economic element is to support the burgeoning local food-growing initiatives, enabling funds to be recycled back into projects, provide tools/training for community members and anything else which is required.

A final theme surrounded the involvement of schools and how IET has engaged children and adults who had little knowledge about growing food. Education is essential with regards to UA; engaging the younger generation can often ensure buy-in, less vandalism and a generation open to such radical ideas (Reynolds, 2008). In this context, Todmorden High School is largely associated with IET as it is home to the Incredible Aqua Garden which combines stateof-the-art aquaponics and hydroponics. This creates a unique learning environment and provides more local food for the community and school. As a nearby resident discussed, the Aqua Garden is great for local students: 'the Aqua Farm seems like a great idea, I didn't really get to see it when I was in sixth form but I have heard it is all state of the art which is great for the students and the school'. 


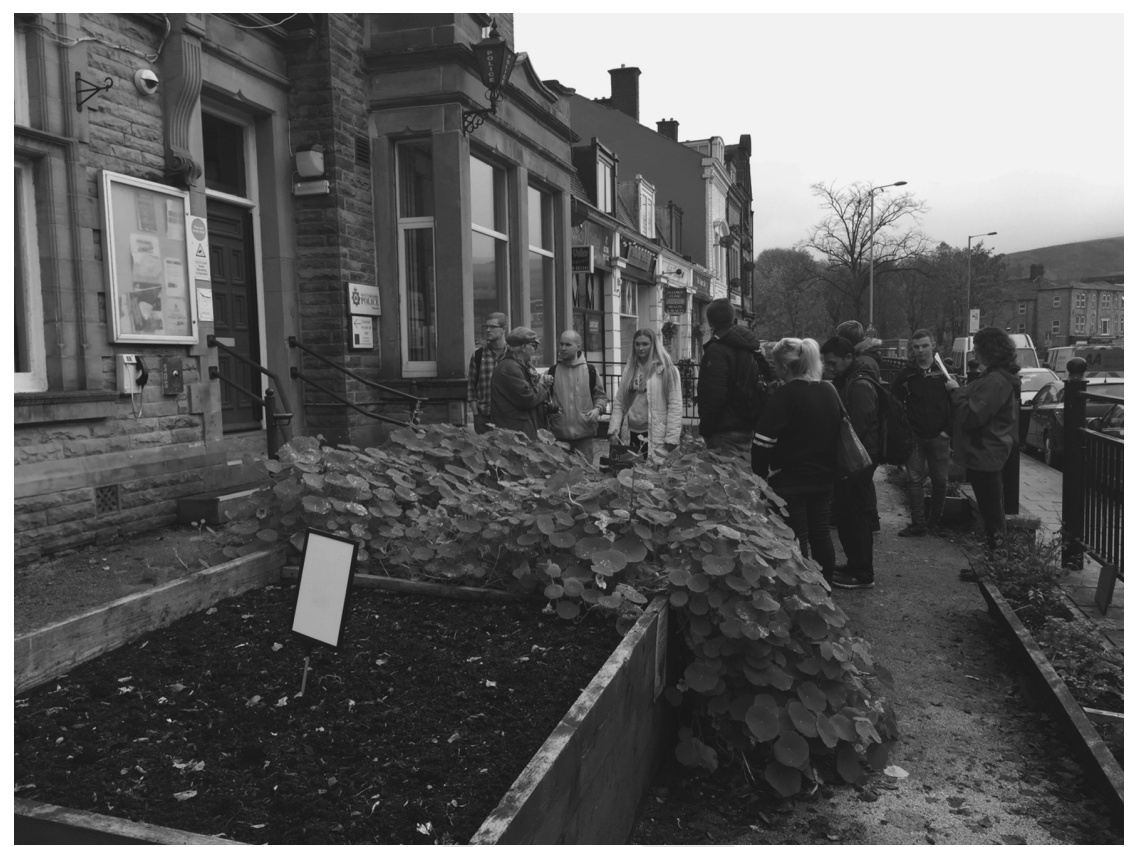

Figure 9.2 Raised beds at Todmorden train station

\section{Hindrances of the IET approach}

As mentioned previously, the literature surrounding IET is overwhelmingly positive and does not take into account the local residents' opinions of the project. In this section we now proceed to challenge the basic notion that IET creates a more just food system and that there are still some obstacles to overcome to achieve this ambitious aim. Due to the small nature of Todmorden, interviewees were made anonymous as per the rest of this chapter to ensure confidentiality. This allowed residents to speak openly about the project to researcher Barker whilst she was in the field collecting data.

The first theme we discovered was the lack of understanding with regards to IET's purpose. It quickly became apparent that residents did not always understand the concept and the group's goals. When asked about the IET's activities and what they aim to achieve, one resident replied 'not particularly no, I know they plant vegetables but I don't know why, it all seems a bit pointless'. This resident was not alone in their confusion and lack of understanding. It appears that many residents felt left out of the scheme and did not know how to get involved with IET. One resident even argues that the food for everyone philosophy does not work: 'I thought it was pretty useless because nobody even picks the vegetables or uses it, I don't think it's worth it just for a few leaves, I'd much rather it wasn't there.' They expanded on this point and appeared to believe that social norms 
prevented many residents picking the free produce; they would be seen as poor and unable to afford produce from mainstream supermarkets. In many ways such a fear is not new and has been witnessed in other UA projects (see for instance St. Clair et al., 2017).

A second theme that came about during the interviews was the untidiness of the planters. A number of residents complained that the raised beds were not taken care of and started to look like 'jungles at the side of the road'. It is clear that some of the residents believe IET is not maintaining the beds well enough all year round. As another Todmorden resident argued, 'I'm not a great lover of it, I mean some of these things that they have about just look like jungles; that Pollination Street on the market looks like a mess it doesn't enhance the town it makes it look worse'. Ironically, Pollination Street (Figure 9.3) is consciously planned in such a way to ensure it is appropriate for the bees.

Another theme surrounded maintenance and how some areas looked scruffy in nature. For example, whilst walking around Todmorden it was clear that some raised beds were poorly maintained. Figure 9.3 shows some beds outside of a nursing home in the town centre which are in a state of disrepair. The images in this figure were taking during the growing season and not at a point one would expect the raised beds to be without vegetation. This issue has been witnessed with other UA projects, particularly guerrilla gardening, in which regular maintenance has been an issue (Hardman and Larkham, 2014).

A third negative perception reported surrounded the placement of raised beds on busy pavements (see Figure 9.4). Some residents believe that the raised beds on public footpaths are an obstruction and should not be there. A Todmorden resident gave their views about the raised bed along pavements:

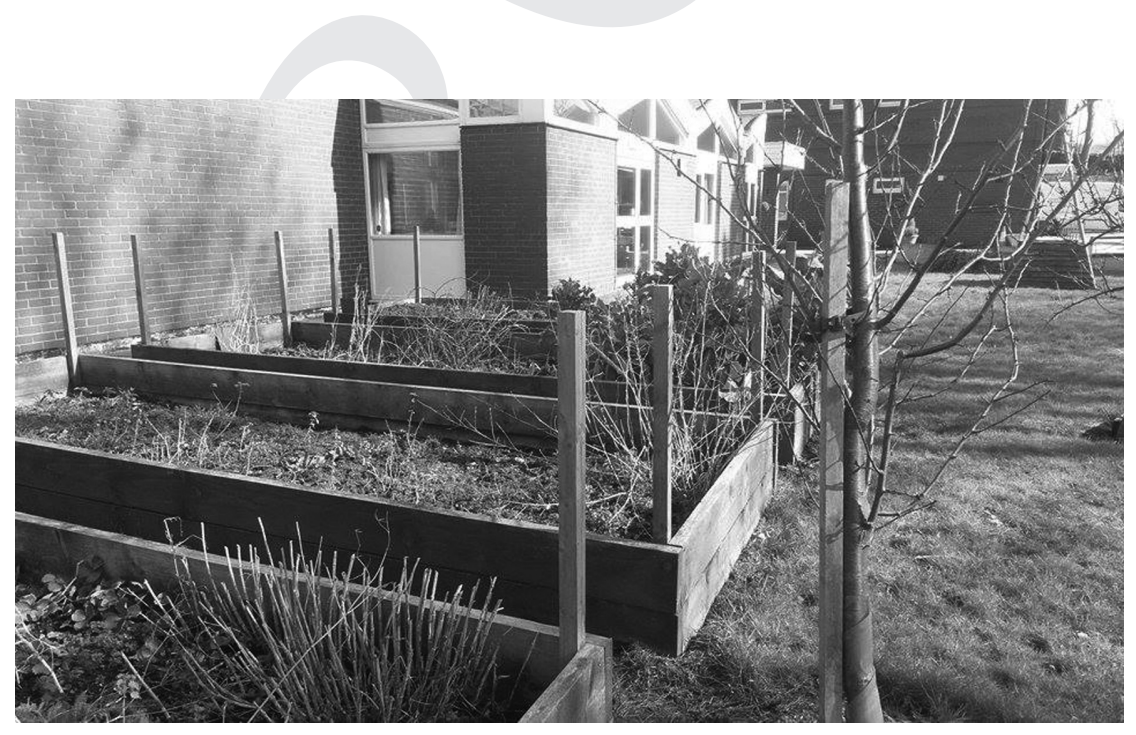

Figure 9.3 Neglected raised beds in Todmorden 


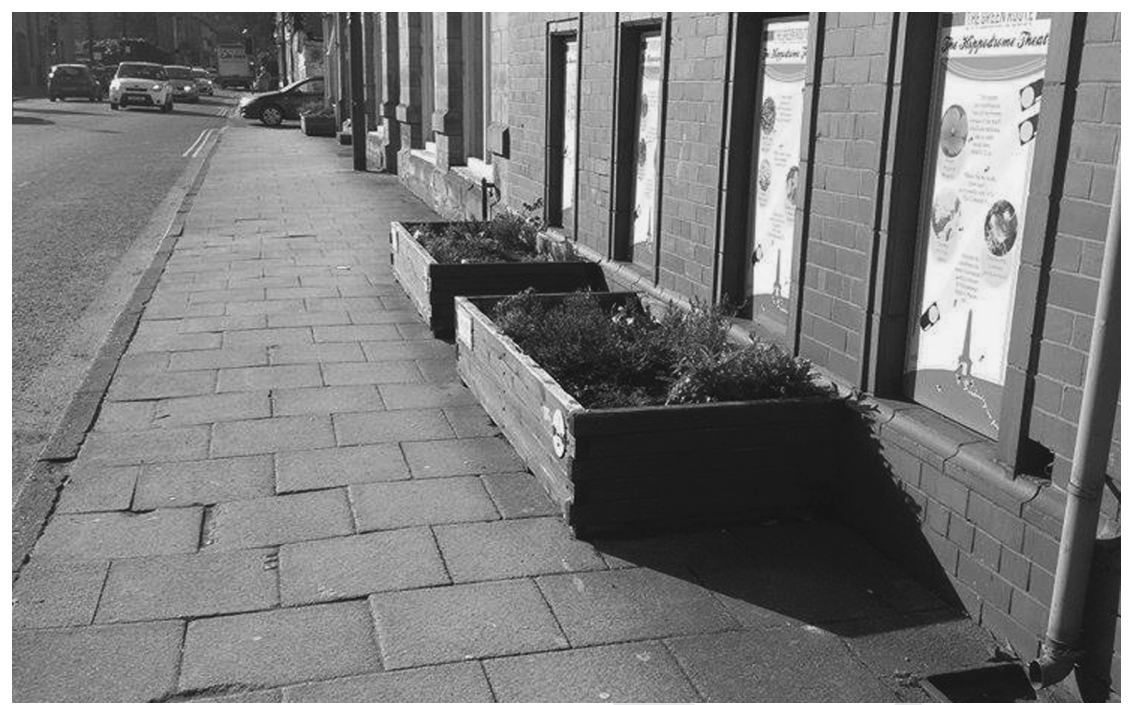

Figure 9.4 Raised beds on a pavement next to a busy road

Some [raised beds] I don't think should be there, like on public foot paths where they are obstructions and obstacles on the footpath, like outside the Hippodrome [Theatre] they take up quite a bit of room and are obstacles for people with disabilities or with prams ... the planters need to be tended to more to keep them looking nice and some of these on the pavement could do with removing, I don't agree with them at all, pavements are for walking on not for growing things.

Finally, residents complained that IET was not appropriate for such an urbanised environment, due to vandalism and its exposure to environmental hazards. For example, a resident explained how IET's work could portray her town in a negative light: 'I don't think it gives off the best impression really some of them have been vandalised and there is litter just thrown in them.' The risk factor was also documented by a fellow resident who argued that 'I wouldn't pick any, I don't want to pick something that's been vandalised or had litter chucked on it, dogs might have even had a wee on it you just don't know!' In both cases, the lack of security resulted in negative perceptions by the residents of the UA projects. In one case, the proximity to roads, car parks and the town as a whole was a barrier to being involved. In a similar manner to most points here this has been raised with other UA projects, including guerrilla gardening (Reynolds, 2008).

\section{Reviewing the potential of the IET model}

Our data collection presents the first critical analysis of IET and demonstrates the need to look beyond the veil. It must be noted that the critical remarks 
from the community are similar to that of other UA schemes: risk, security, maintenance and participation. Although these themes have appeared before, this is the first time they have been raised in the Todmorden context. In this sense the results demonstrate that IET, although perhaps more successful than most UA projects, still faces similar issues. Perhaps the largest obstacle is to make IET appealing to the population who feel disenfranchised. Whilst some 5,000 residents are involved, this still leaves around 10,000 without any direct involvement with IET, a concept which has revolutionised their town. There is a disconnection at present between IET members/volunteers and residents not involved or aware fully of the concept.

It could be said that IET may fall under Born and Purcell's $(2006 ; 2009)$ idea of the local trap. Born and Purcell $(2006 ; 2009)$ argue that food systems have become increasing established within the urban environment, however they believe that local food systems are no more likely to be sustainable than systems on other scales. Born and Purcell (2006: 195) argue that 'the local trap is not an argument against the local scale per se, rather the local trap is the assumption that local is inherently good'. In the case of IET the literature often focuses on how successful the scheme has been for the town and how it is good for the local residents. However, using the example of the local trap, the benefits of IET can be exaggerated and romanticised which is in keeping with the discourse of the local equalling better. Again, as academics there is an urgent need to employ a critical lens in order to avoid the trap. Although IET's contribution to the food system has not been explored in this chapter, its function and connection to the community has been covered, revealing some results not previously seen.

Despite the critique of IET, it must be noted that the group has made remarkable progress since its inception in 2008. IET now ranks amongst the largest and well-known UA movements and proves that guerrilla gardening can lead to success. With the latter, this is an important point and should demonstrate to key decision-makers the power and potential of the informal movement. With local authorities beginning to embrace guerrilla activity, we could see more IET movements appearing in the near future. In terms of creating a more just food system, IET has been a tool for making great strides through creating new growing spaces, upskilling the community and providing support for growing activities.

IET actively labels itself as a group that aims to tackle social injustices and enable a food-for-all philosophy (Guardian, 2012). With this in mind, our study shows that IET is making great strides to realising this ambitious aim and, whilst there are negative comments, most of these surround a lack of understanding rather than genuine concerns. The overwhelming majority of interviewees provided a positive review of IET's actions, arguing that the group bring social, environmental and even economic benefits. With the latter, tourism has increased and Todmorden is now known globally, with tours regularly operated around the town. 


\section{Concluding remarks}

This study sought to critically explore IET through engaging with local residents in Todmorden. Our key findings reveal the community's overly positive experiences of the project and provide a basis through which to improve practice and that of the wider network; although there were some critiques of the scheme, these were somewhat minor in comparison. On a wider note, we also demonstrate how the majority of the public engage well with the idea of UA and could potentially warm to the notion of upscaling. With more local authorities investing in high-tech and large-scale UA, projects like IET provide a mechanism for the community to understand the basic concept before more radical options, such as high-tech and large-scale, are introduced.

Ultimately, IET has been able to generate interest in UA across a wide array of other towns and cities. In the UK alone there are over a hundred active groups following the model and using IET's online tools. Each of these groups aims to achieve IET's success through replicating activities and learning lessons from the original. Through doing so, the groups are able to operate in a more sustainable manner as they form part of this wider network. IET has been the catalyst for spreading UA in the UK and has engaged tens of thousands of people through its wider model.

As we have argued throughout this chapter, IET has made huge contributions to the food justice movement. Although our focus has been on the local context, its origins in Todmorden, it must be noted that the wider network has put into practice the original model and this has resulted in significant impacts globally; ultimately, IET has helped to advance the food justice movement in a wide range of countries. On a basic level this has been through the creation of more UA spaces, but the education programme and other elements have also been replicated through organisations using the Incredible Network's online tools. This in turn has allowed countless communities to exercise their right to more local, healthy produce to cook and sell as they see fit (Justfood.org, n.d.).

Further research is required on this wider network and internationally to understand the models used in more detail. A critical lens should be adopted in all instances to view practice and those affected by the various projects. More work is also needed on the potential to upscale activities and evaluate options for expanding the IET model to make a real impact on health and wellbeing, urban economies and social cohesion.

\section{References}

Adams, D. and Hardman, M. (2014): Observing guerrillas in the wild: reinterpreting practices of informal gardening. Urban Studies 51 (6): 1103-1119.

Adams, D., Hardman, M. and Scott, A. (2014): Guerrilla warfare in the planning system: revolutionary progress towards sustainability? Geografriska Annaler Series B: Human Geography 95 (4): 375-387. 
Alkon, A. H. and Agyeman, J. (2011): Cultivating Food Justice. Boston: MIT Press.

Allen, M. (2014): Guerrilla gardening in the UK is a sign of failure. www.theguardian.com/ lifeandstyle/gardening-blog/2014/oct/22/guerrilla-gardening-uk-failure (accessed 13 July 2017).

Born, B. and Purcell, M. (2006). Avoiding the local trap: scale and food systems in planning research. Journal of Planning Education and Research 26 (2): 195-207.

Born, B. and Purcell, M. (2009): Food systems and the local trap. In: Inglis, D. and Gimlin, D. (Eds): The Globalization of Food. Oxford: Berg, 117-139.

Breitbach, C. (2007): The geographies of a more just food system: building landscapes for social reproduction. Landscape Research 32 (5): 533-557.

Caputo, S. (2012): The purpose of urban food production in developed countries. In: Viljoen, A. and Wiskerke, J. S. C. (Eds.): Sustainable Food Planning: Evolving Theory and Practice. Wageningen: Wageningen Academic Publishers, 259-270.

Chipungu, L., Magidimisha, H., Hardman, M. and Beesley, L. (2013): The importance of soil quality in the safe practice of urban agriculture: an exploration of the practice in Harare, Nairobi and Johannesburg. In: Thomas, A. and Brearley, F. (Eds): Land-Use Change Impacts on Soil Processes in Tropical and Savannah Ecosystems. Surrey: CABI, 72-84.

Crane, A. (2011): Intervening with agriculture: a participatory action case study of guerrilla gardening in Kingston, Ontario. Unpublished Master's dissertation. Queen's University, Canada.

Crane, A., Viswanathan, L. and Whitelaw, G. (2012): Sustainability through intervention: a case study of guerrilla gardening in Kingston, Ontario. Local Environment: The International Journal of Justice and Sustainability 18: 71-90.

Giorda, E. (2012): Farming in Mowtown: competing narratives for urban development and urban agriculture in Detroit. In: Viljoen, A. and Wiskerke J. S. C. (Eds): Sustainable Food Planning: Evolving Theory and Practice. Wageningen: Wageningen Academic Publishers, 271-282.

Glaser, B. C. and Strauss, A. L. (1967): The Discovery of Grounded Theory: Strategies for Qualitative Research. Chicago: Aldine Publishing Company.

Gorgolewski, M., Komisar, J. and Nasr, J. (2011): Carrot City: Creating Places for Urban Agriculture. New York: Monacelli Press.

Guardian (2012): Free food, caring and sharing: new spirit of community in Yorkshire. www.theguardian.com/society/2012/may/06/lifestyle-communities-hebden-bridgetodmorden (accessed 1 July 2017).

Hardman, M. and Larkham, P. J. (2014): Informal Urban Agriculture. London: Springer.

IET (2017): What we do. www.incredible-edible-todmorden.co.uk/projects (accessed 20 March 2017).

Johnson,L.(2011): City Farmer:Adventuresin Growing Urban FoodVancouver: Greystone Books.

Justfood.org (n.d.) What is food justice? http://justfood.org/advocacy/what-is-foodjustice (accessed 7 October 2017).

Lewis, T. (2012): 'There grows the neighbourhood': green citizenship, creativity and life politics on eco-TV. International Journal of Cultural Studies 15 (3): 315-326.

McKay, G. (2011): Radical Gardening: Politics, Idealism and Rebellion in the Garden. London: Frances, Lincoln.

Paull, J. (2011): Incredible Edible Todmorden: eating the street. Farming Matters 27 (3): 28-29.

Reynolds, R. (2008): On Guerrilla Gardening: A Handbook for Gardening without Permission. London: Bloomsbury.

Scott, A. J., Carter, C. E., Larkham, P., Reed, M., Morton, N., Waters, R., Adams, D., Collier, D., Crean, C., Curzon, R., Forster, R., Gibbs, P., Grayson, N., Hardman, M., Hearle, A., 
Jarvis, D., Kennet, M., Leach, K., Middleton, M., Schiessel, N., Stonyer, B. and Coles, R. (2013). Disintegrated development at the rural urban fringe: re-connecting spatial planning theory and practice. Progress in Planning 83: 1-52.

St. Clair, R., Hardman, M., Armitage, R. P. and Sheriff, G. S. (2017): The trouble with temporary: impacts and pitfalls of a meanwhile community garden in Wythenshawe, South Manchester. doi: 10.1017/S1742170517000291.

Tornaghi, C. (2014): Critical geography of urban agriculture. Progress in Human Geography 38 (4): 551-567. doi: 10.1177/0309132513512542

Viljoen, A. (Ed.) (2005): CPULs: Continuous Productive Urban Landscapes. Oxford: Architectural Press.

Wiskerke J. S. C. and Viljoen, A. (2012): Sustainable urban food provisioning: challenges for scientists, policymakers, planners and designers. In: Viljoen, A. and Wiskerke J. S. C. (Eds): Sustainable Food Planning: Evolving Theory and Practice. Wageningen: Wageningen Academic Publishers, 19-36.

Zanetti, O. (2007): Guerrilla gardening - geographers and gardeners, actors and networks: reconsidering urban public space. Unpublished MA dissertation. Queen Mary, University of London. 